\title{
A MULTI-OBJECTIVE OPTIMIZATION FOR PERFORMANCE IMPROVEMENT OF THE Z-SOURCE ACTIVE POWER FILTER
}

\author{
Seyed Mohsen Hosseini — Yousef Alinejad Beromi
}

\begin{abstract}
The high power dissipation is one of the most important problems of the z-source inverter (ZSI). By using an appropriate optimization scheme, the losses can be significantly reduced without any negative impact on the other characteristics of the inverter. In this paper, a multi-objective optimization is implemented in order to reduce the ZSI total losses as well as to improve the z-source active power filter (APF) performance. The optimization is focused on the four important objectives including power losses of the Z-source APF, the initial cost of the system components, the voltage and current ripples, and the boost factor of the z-source network. For these purposes, the multi-objective genetic algorithm (MOGA) is employed. The numerical and simulation results are presented to evaluate the optimization performance. The results show that a good balance can be achieved between the switching power losses, the voltage-current ripple levels, the component costs and the boost factor using the optimized parameters.

K e y ords: active power filters, Z-source inverter, switching loss, parameter optimization, multi-objective genetic algorithms
\end{abstract}

\section{INTRODUCTION}

The active power filter is an effective device for mitigate the load current harmonics and compensate the reactive power. The inverter of the active power filter is one of the most important parts of it. The function of inverter is to generate the compensation current. In the traditional active filter topologies, a voltage source inverter (VSI) or current source inverter (CSI) are used [14]. These topologies have many disadvantages and limits, such as the need for a large capacitor in the DC-link, only buck mode operation, the requirement for dead time between PWM duty cycles, and noise issues due to electromagnetic interference [5]. To overcome these problems, a new inverter topology known as impedance source inverter (ZSI) has attracted a lot of attention recently [6-9]. Some advantages of ZSI compared to the previous structures are the ability to increase or decrease the voltage over a wide range by setting the shoot-through (ST) time interval, the possibility of shoot-through without damaging of the switches, a second order filtering by impedance network and power quality improvement, the high switching frequency of the impedance network which is 6 times more than inverter frequency leading to size reduction of the elements, less influence of EMI noise, and etc [10,11]. Figure 1 shows the schematic of a three-phase ZSI active filter connected to the grid.

Despite its many benefits, one of the major problems in the ZSI topology is the high switching power loss versus traditional inverter structure [12-14].

In the previous literature, some techniques have been proposed to reduce the ZSI losses and improve the efficiency. In [14], the Si-based power devices of the ZSI are replaced by new SiC-based power devices. Although the SiC-based power devices can partially reduce the total losses, the some disadvantages such as technological restrictions, limited availability, and need for hightemperature packaging techniques, that have not yet been developed, limit its widespread use [15]. In [16] and [17], reducing the switching losses is performed only by changing of the PWM pattern and ST time interval. Although appropriate adjustment of ST can effect on the inverter losses, but it is not enough. The loss compensation and the efficiency improvement in this method are not significant. In addition, this technique may have a negative effect on the boost factor (BF) of the ZSI.

It is possible to effectively reduce the overall losses of the ZSI by appropriate choice of the parameters and elements values. However, on the other hand, a large variation in the ZSI parameters can cause performance degradation, quality reduction of the waveforms, and cost rising. Therefore, finding the optimal points to establish a balance needs to solve optimization problem with multiple equations and parameters. Due to the nonlinear nature of the equations, the multi-objective optimization algorithm can achieve a good result. Thus, in this paper, an equilibrium is established between the switching power losses function, the initial cost of filter elements, the capacitor voltage and inductor current ripples, and the boost factor of the impedance network in the ZSI active power filter by multi-objective genetic algorithm (MOGA) to improve the filter performance.

The results evaluate effectiveness of optimized filter, where the loss reduction is equal to $39.5 \%$, the cost reduction is $8.43 \%$, and the current ripple improvement is $57.03 \%$.

* Department of Electrical Engineering, Semnan University, Semnan, Iran, Yalinejad@semnan.ac.ir 


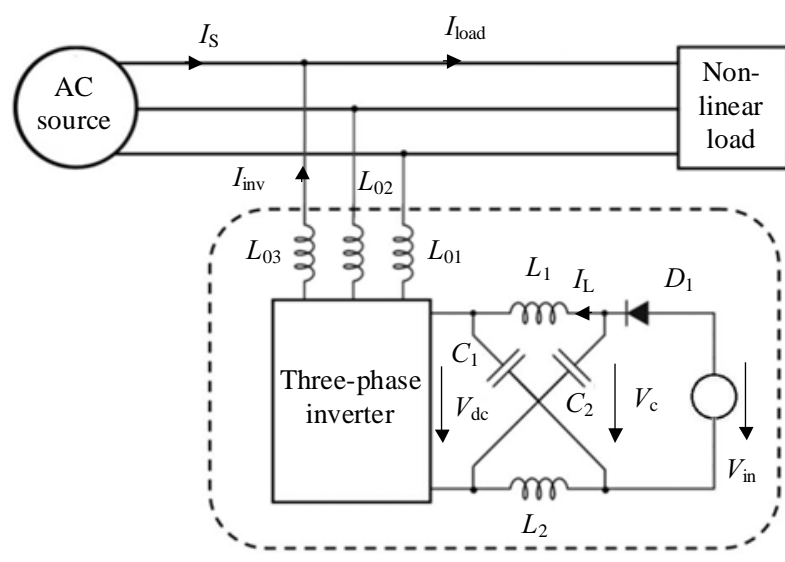

Fig. 1. The ZSI shunt active power filter

\section{POWER LOSS PROBLEM IN THE ZSI STRUCTURE}

One of the popular methods for producing the proper DC-link voltage of the inverter is using a DC/DC boost converter that is connected in parallel to the VSI. Although the VSI with the boost converter has one more IGBT switch compared to the ZSI, but the power loss in the ZSI structure is significantly higher [7,8]. Accordingly, the efficiency of ZSI structure is lower. In general, four different types of losses occur in the semiconductor devices including driving, conduction, off-state and switching losses. The driving and off-state losses versus the conduction and switching losses are negligible due to very small values [7].

In the shoot-through state where the DC source is short circuit, the current through the IGBT is sum of sinusoidal network current and high frequency shootthrough current. The conduction losses of the IGBTs can be calculated by RMS and mean currents through it, as

$\mathrm{P}_{\mathrm{C}, \mathrm{ZSI}}^{\mathrm{IGBT}}=V_{\mathrm{CE}, 0} \overline{\mathrm{i}}_{v}+r_{\mathrm{CE}} \tilde{\mathrm{i}}_{v}^{2}=V_{\mathrm{CE}, 0}\left(\overline{\mathrm{i}}_{\mathrm{L}}+\overline{\mathrm{i}}_{\mathrm{ST}}\right)+r_{\mathrm{CE}}\left(\overline{\mathrm{i}}_{\mathrm{L}}+\tilde{\mathrm{i}}_{\mathrm{ST}}\right)^{2}$

where $V_{\mathrm{CE}, 0}$ and $r_{\mathrm{CE}}$ denote the threshold voltages and differential resistances of the IGBT, $\overline{\mathrm{i}}_{v}$ and $\tilde{\mathrm{i}}_{v}$ are the mean and the RMS values of the current through the valves, respectively. $\overline{\mathrm{i}}_{\mathrm{ST}}$ and $\tilde{\mathrm{i}}_{\mathrm{ST}}$ are mean and RMS values of the shoot-through current, $\overline{\mathrm{i}}_{\mathrm{L}}$ is mean value of the line current which are calculated by Equations (2) to (4), respectively.

$$
\begin{aligned}
& \overline{\mathrm{i}}_{\mathrm{ST}}=\frac{P_{\mathrm{in}}}{v_{\text {in }}} \frac{2}{3} D_{0}, \\
& \tilde{\mathrm{i}}_{\mathrm{ST}}=\left\{\frac { T _ { 0 } } { T } \left[\left(\frac{2 P_{\text {in }}}{3 V_{\text {in }}}+\frac{T_{0}}{4 L} V_{\mathrm{c}}\right)^{2}\right.\right.-\left(\frac{P_{\text {in }}}{3 V_{\text {in }}}+\frac{T_{0}}{2 L} V_{\mathrm{c}}\right) \frac{1}{L} V_{\mathrm{c}} T_{0} \\
&\left.\left.+\frac{1}{12 L^{2}} V_{\mathrm{c}}^{2} T_{0}^{2}\right]\right\}^{1 / 2} \\
& \overline{\mathrm{i}}_{\mathrm{L}}=\frac{P_{\text {in }}}{V_{\text {out } 2 \mathrm{~L}}} \sqrt{\frac{2}{3}} M \cos \varphi
\end{aligned}
$$

where $P_{\text {in }}$ and $V_{\text {in }}$ are input power and voltage of the inverter, $D_{0}$ is shoot-through duty cycle, $L$ is inductance of the impedance network, $V_{\mathrm{c}}$ is capacitor voltage, $M$ is modulation index, and $\cos \varphi$ is power factor. The freewheeling diodes conduct only during the zero-states of switch and this has led to conducting losses for the diodes in accordance with the following formula

$$
\begin{aligned}
P_{\mathrm{C}, \mathrm{ZSI}}^{\text {Diode }}=\left(\frac{V_{\mathrm{F}, 0} \hat{\mathrm{i}}_{L}}{2 \pi}\left(1-\frac{M \pi}{4} \cos \varphi\right)+\right. \\
\left.\quad \frac{r_{\mathrm{F}} \hat{\mathrm{i}} L^{2}}{2 \pi}\left(\frac{\pi}{4}-M \frac{2}{3} \cos \varphi\right)\right) \frac{\sqrt{3}(3-\pi)}{3 \sqrt{3} M-2 \pi}
\end{aligned}
$$

where $V_{\mathrm{F}, 0}$ is diode threshold voltage and $r_{\mathrm{F}}$ is differential resistance. The DC side diode $\left(D_{1}\right)$ is conducted during the active-state of IGBTs and is blocked in the shoot-through interval. Therefore, the diode conduction losses can be described as

$$
\begin{aligned}
& P_{\mathrm{C}, \mathrm{ZSI}}^{\mathrm{D} 1}=V_{\mathrm{F}, 0} \frac{P_{\text {in }}}{V_{\text {in }}}+r_{\mathrm{F}} {\left[\left(\frac{P_{\text {in }}}{V_{\text {in }}} \frac{T}{T-T_{0}}+\frac{T-T_{0}}{T}-\right.\right.} \\
& \frac{1}{L}\left(V_{\mathrm{in}}-V_{\mathrm{c}}\right)\left(\frac{P_{\text {in }}}{v_{\text {in }}} \frac{T}{T-T_{0}}+\frac{T-T_{0}}{2 L}\left(V_{\mathrm{in}}-V_{\mathrm{c}}\right)\right) \frac{\left(T-T_{0}\right)^{2}}{T} \\
&\left.\quad-\frac{1}{3 L^{2}}\left(V_{\mathrm{in}}-V_{\mathrm{c}}\right)^{2} \frac{\left(T-T_{0}\right)^{3}}{T}\right]
\end{aligned}
$$

The switching losses are a function of the switching frequency, voltage and current as well as type of the PWM method and the switching energies of the IGBT $\left(\mathrm{E}_{\mathrm{on}}\right.$, $\left.\mathrm{E}_{\mathrm{off}}\right)$ and diode $\left(\mathrm{E}_{\mathrm{rec}}\right)$. For Z-source inverter, the switching losses for each IGBT, anti- parallel freewheeling diode and input diode are shown in the following equations

$$
\begin{aligned}
& P_{\mathrm{S}, \mathrm{ZSI}}^{\mathrm{IGBT}}=f_{\mathrm{s}}\left(\mathrm{E}_{\mathrm{on}}+\mathrm{E}_{\mathrm{off}}\right)\left(\frac{1}{\pi} \frac{\hat{\mathrm{v}}_{\mathrm{dc}}}{\mathrm{v}_{\text {ref }}} \frac{\hat{\mathrm{i}}_{\mathrm{L}}}{\dot{\mathrm{i}}_{\text {ref }}}\right. \\
& \left.+\frac{\hat{\mathrm{v}}_{\mathrm{dc}}}{\mathrm{v}_{\text {ref }}} \frac{2 P_{\text {in }}}{3 V_{\text {in }} \mathrm{i}_{\text {ref }}}\right) \mathrm{N}_{\text {con } / \text { disc }}, \\
& P_{\mathrm{S}, \mathrm{ZS} 1}^{\text {Diode }}=\frac{1}{\pi} f_{\mathrm{s}} \mathrm{E}_{\mathrm{rec}} \frac{\hat{\mathrm{v}}_{\mathrm{dc}}}{\mathrm{v}_{\text {ref }}} \frac{\mathrm{i}_{\mathrm{L}}}{\mathrm{i}_{\text {ref }}} \mathrm{N}_{\text {con/disc }}, \\
& P_{\mathrm{S}, \mathrm{ZSI}}^{\mathrm{D} 1}=2 f_{\mathrm{s}} \mathrm{E}_{\mathrm{rec}, \mathrm{D} 1}=\frac{V_{\mathrm{c}}-V_{\mathrm{in}}}{\mathrm{v}_{\mathrm{ref}}} \times \\
& \frac{\frac{P_{\text {in }}}{V_{\text {in }}} \frac{T}{T-T_{0}}-\frac{1}{2 L}\left(V_{\text {in }}-V_{\mathrm{c}}\right)\left(T-T_{0}\right)}{\mathrm{i}_{\text {ref }}} \mathrm{N}_{\mathrm{con} / \mathrm{disc}}
\end{aligned}
$$

The factor $\mathrm{N}_{\text {con/disc }}$ depends on PWM type, which is 0.5 for discontinuous and 1 for continuous PWM. The total loss of the ZSI including the conduction and switching losses of the semiconductors is equal to

$$
\begin{array}{r}
P_{\mathrm{ZSI}}^{\mathrm{Tot}}=6\left(P_{\mathrm{C}, \mathrm{ZS} 1}^{\mathrm{IGBT}}+P_{\mathrm{C}, \mathrm{ZSI}}^{\mathrm{Diode}}+P_{\mathrm{S}, \mathrm{ZSI}}^{\mathrm{IGBT}}+P_{\mathrm{S}, \mathrm{ZSI}}^{\mathrm{Diode}}\right) \\
+P_{\mathrm{C}, \mathrm{ZS} 1}^{\mathrm{D} 1}+P_{\mathrm{S}, \mathrm{ZSI}}^{\mathrm{D} 1}
\end{array}
$$




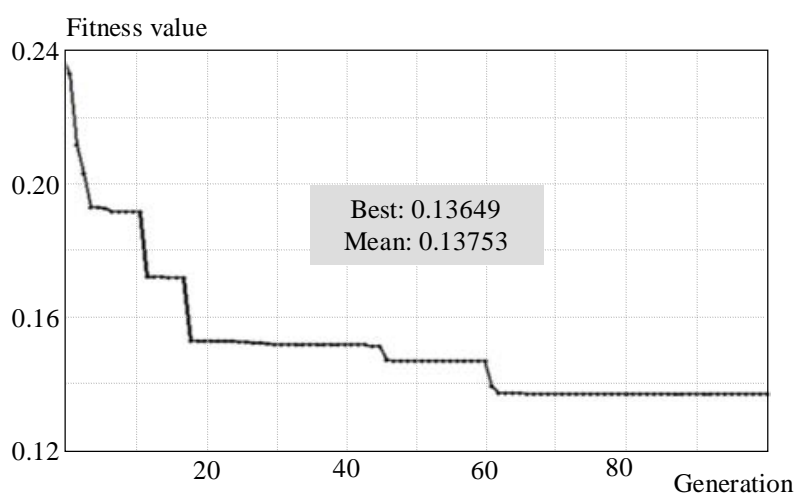

Fig. 2. MOGA search process for finding the optimal points in the response space

Table 1. System and parameters specifications

\begin{tabular}{|c|c|}
\hline Source characteristic & $220 v_{\mathrm{rms}}-50 \mathrm{~Hz}$ \\
\hline Variations of $L_{1}$ and $L_{2}$ & {$\left[\begin{array}{ll}450 & 2000] \mu \mathrm{H}\end{array}\right.$} \\
\hline Variations of $C_{1}$ and $C_{2}$ & {$\left[\begin{array}{llll}300 & 1500\end{array} \mu \mathrm{F}\right.$} \\
\hline Switching frequency $\left(f_{\mathrm{s}}\right)$ & $10 \mathrm{KHz}$ \\
\hline Variations of $T_{0}$ & {$\left[\begin{array}{lll}0.0304 & 0.0450\end{array}\right] \mathrm{ms}$} \\
\hline Input voltage $V_{\text {in }}$ & $270 \mathrm{~V}$ \\
\hline Cut-off frequency & $1 \mathrm{KHz}$ \\
\hline Output voltage $V_{(\mathrm{inv} 2, \mathrm{~L} 2 \mathrm{~L})}$ & $381 \mathrm{~V}_{\mathrm{rms}}$ \\
\hline$N_{(\text {con } / \text { disc })}$ & 1 \\
\hline
\end{tabular}

Table 2. Weights of objective functions

\begin{tabular}{cc}
\hline$W_{1}$ & 0.45 \\
$W_{2}$ & 0.25 \\
$W_{3}$ & 0.10 \\
$W_{4}$ & 0.20 \\
$\alpha$ & $0.8(\mathrm{pu} / \mu \mathrm{H})$ \\
$\beta$ & $2(\mathrm{pu} / \mu \mathrm{H})$ \\
\hline
\end{tabular}

Table 3. Tuned parameters for genetic algorithm

\begin{tabular}{cc}
\hline Chromosomes coding & Binary \\
Initial population & 50 \\
Generation of initial population & Random \\
Selection function & Roulette \\
Crossover type & Single point \\
Percentage of Crossover & $\% 75$ \\
possibility of mutation & $\% 5$ \\
Maximum generation & 100 \\
\hline
\end{tabular}

\section{DEFINITION OF THE OBJECTIVE FUNCTIONS AND DECISION VARIABLES}

In addition to the loss function, there are three other objectives that have to be considered for optimization the performance of ZSI active filter. Consequently, there will be a total of 4 optimization targets, as following:

- the power losses of the ZSI,

- the initial cost of the filter elements,

- the boost factor (BF) of the impedance network,

- the capacitor voltage and inductor current ripples.
The optimization algorithm is applied to the first and second objective functions to reduce losses and increase overall efficiency, and also reduce initial costs of the active filter structure. Hence, the parameters searching are carried out with the purpose of minimizing any two functions. But the target of third objective function is prevention of dropping of the boost factor and establishes the appropriate balance between the objectives. Thus the third objective function should be maximized. If the inductor and capacitor values of the impedance network choose less than of the certain level (for minimizing the cost function), the fluctuation of the capacitor voltage and inductor current waveforms increases. The ripple function is dependent to the parameters like capacitor and inductor value, and ST time which should be minimized. The conduction losses that are a major part of the total losses $\left(P_{\mathrm{C}, \mathrm{ZSI}}^{\mathrm{IGBT}}\right)$, diode conduction losses $\left(P_{\mathrm{C}, \mathrm{ZSI}}^{\mathrm{D} 1}\right)$ and diode switching losses $\left(P_{\mathrm{S}, \mathrm{ZSI}}^{\mathrm{D} 1}\right)$ are dependent on the selected parameters and it is possible to optimize its value. Therefore, the objective function of the ZSI losses is formed of the total conduction losses of the six numbers of IGBTs (in the 3-phase inverter) and total losses of the input diode.

$$
F_{1}\left(T_{0}, L, C\right)=\left[\sum_{(n=1)}^{6} P_{\mathrm{C}, \mathrm{ZSI}}^{\mathrm{IGBT}_{n}}\right]+P_{\mathrm{C}, \mathrm{ZSI}}^{\mathrm{D} 1}+P_{\mathrm{S}, \mathrm{ZSI}}^{\mathrm{D} 1}
$$

where $T_{0}$ is shoot-through time, $L$ and $C$ are inductor and capacitor of the impedance network, respectively. One important factor in the design of active filters is the initial and operation cost. There, the filter operation cost saving is obtained from the filter losses optimization, and to reduce initial cost, other objective function is defined encompassing the Z-network inductor and capacitor costs according to

$$
F_{2}(L, C)=\operatorname{Cost}(L, C)=\alpha \sum_{n=1,2} L_{n}+\beta \sum_{n=1,2} C_{n}
$$

where $\alpha$ and $\beta$ are cost rising coefficient for increasing in the amount of Z-source inverter inductance $(\mathrm{mH})$ and capacitance $(\mu \mathrm{F})$.

Among the advantages of Z-source inverter is the voltage boost capability which helps to remove extra DC/DC switching converter and large capacitor in DC-link. This capability can be achieved by adjusting the time period ST. Achievement of higher boost factor can be considered as one of the optimization objectives. Also, this ratio should not be less than specific threshold value (ie line voltage peak). For the boost factor, the Equation (13) is considered as objective function.

$$
F_{3}\left(T_{0}\right)=\mathrm{BF}=\left\{\frac{1}{1-2\left(T_{0} / T\right)} .\right.
$$

As mentioned previously, if the Z-network inductor and capacitor values are selected less than certain level 

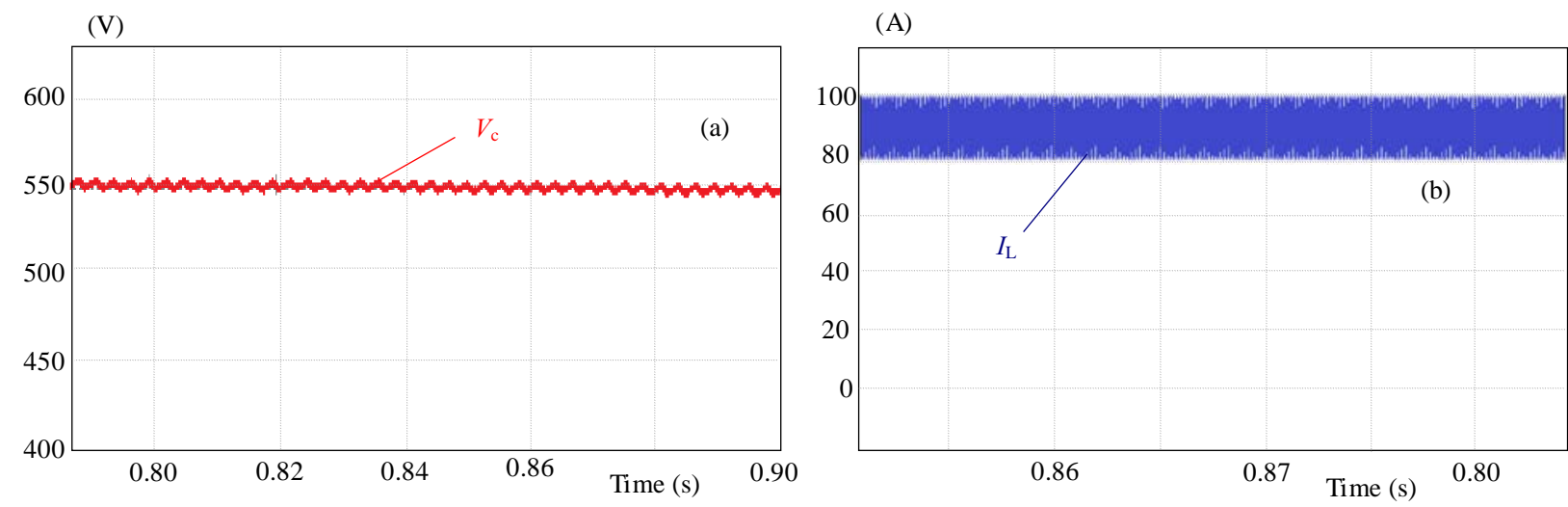

$(\mathrm{kV})$
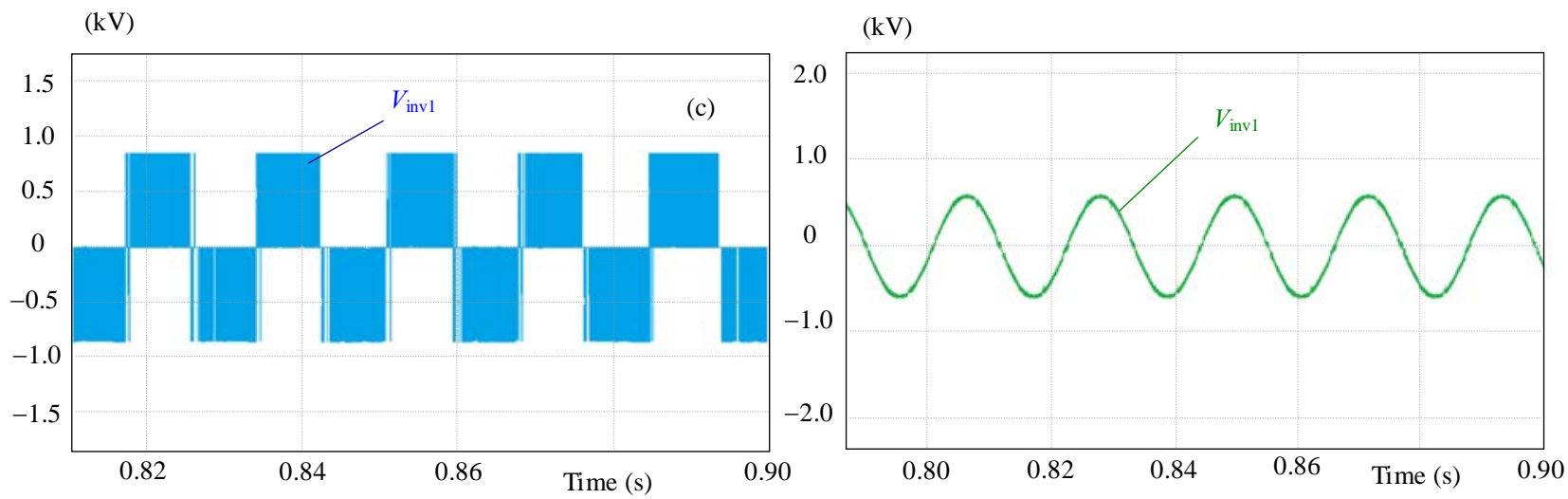

Fig. 3. Simulation waveforms: (a) - capacitor voltage, (b) - inductor current, (c) - ZSI output voltage before filtering, (d) - ZSI output voltage after filtering

Table 4. Comparison between non-optimal point and MOGA results

\begin{tabular}{ccc}
\hline Characteristic & Non-optimal & MOGA \\
\hline$L$ & $750 \mu \mathrm{H}$ & $1065.39 \mu \mathrm{H}$ \\
$C$ & $860 \mu \mathrm{F}$ & $636.05 \mu \mathrm{F}$ \\
$T_{0}$ & $0.0410 \mathrm{~ms}$ & $0.0341 \mathrm{~ms}$ \\
$P_{\text {Tot }}$ & $2035.32 \mathrm{~W}$ & $1229.47 \mathrm{~W}$ \\
Cost & $4640.00 \mathrm{Unit}$ & $4248.82 \mathrm{Unit}$ \\
$B . F$ & 5.550 & 3.125 \\
$\Delta V_{\mathrm{c}}$ & $4.29 \mathrm{~V}$ & $4.81 \mathrm{~V}$ \\
$\Delta \mathrm{I}_{\mathrm{L}}$ & $48.34 \mathrm{~A}$ & $17.77 \mathrm{~A}$ \\
\hline
\end{tabular}

(to reduce filter costs), the rate of fluctuation (ripple) in the capacitor voltage and the inductor current will increase and decrease the quality of the output voltage and current. Therefore, the inductor and capacitor values should be selected considering this issue, and then minimized fluctuations with parameters adjustment in the ripple relationship [18]. According to Equations (14) and (15), which are calculated for the ZSI structure elements, the ripple relations are a function of inductor and capacitor values, and shoot-through time interval.

$$
\begin{aligned}
& \Delta V_{\mathrm{c}}=\frac{I_{\mathrm{L}} T_{0}}{L} \\
& \Delta I_{\mathrm{L}}=\frac{V_{\mathrm{c}} T_{0}}{L}=\frac{T_{0}}{L} \frac{1-\left(T_{0} / T\right)}{1-2\left(T_{0} / T\right)} V_{\mathrm{in}}
\end{aligned}
$$

where $\Delta V_{\mathrm{c}}$ and $\Delta I_{\mathrm{L}}$ are ripple of capacitor voltage and inductor current, respectively. Equation (15) is obtained by relation between capacitor and input voltages in the ZSI structure by

$$
V_{\mathrm{c}}=\frac{1-\left(T_{0} / T\right)}{1-2\left(T_{0} / T\right)} V_{\mathrm{in}} .
$$

The sum of two ripple equations in the ZSI is defined as fourth objective function which should be minimized. Hence, the objective function based on the normalized values of voltage and current ripples wrote as:

$$
\begin{aligned}
F_{4}\left(L, C, T_{0}\right)=\Delta & V_{\mathrm{c}}^{\text {norm }}+\Delta I_{L}^{\text {norm }}= \\
& {\left[\frac{I_{L} T_{0}}{C}\right]^{\prime}+\left[\frac{T_{0}}{L} \frac{1-\left(T_{0} / T\right)}{1-2\left(T_{0} / T\right)} V_{\mathrm{in}}\right]^{\prime} }
\end{aligned}
$$

where $\Delta V_{\mathrm{c}}^{\text {norm }}$ and $\Delta I_{\mathrm{L}}^{\text {norm }}$ are normalized values of capacitor voltage and inductor current, respectively. With respect to the four mentioned objective functions, the process of this optimization is a multi-objective problem. There, in order to calculate the total objective function, the weighted-sum method has been employed [19]. Based on (18) to (19), in this method, all of the objective functions with certain weights are integrated together and the optimization is focused on the overall objective function [20].

$$
\begin{aligned}
F(x) & =\left\{f_{1}(x), \ldots, f_{n}(x)\right\} \\
& =w_{1} f_{1}^{\prime}+w_{2} f_{2}^{\prime}+\cdots+w_{n} f_{n}^{\prime}
\end{aligned}
$$

subject to: $g(x) \leq 0, \quad h(x)=0$. 


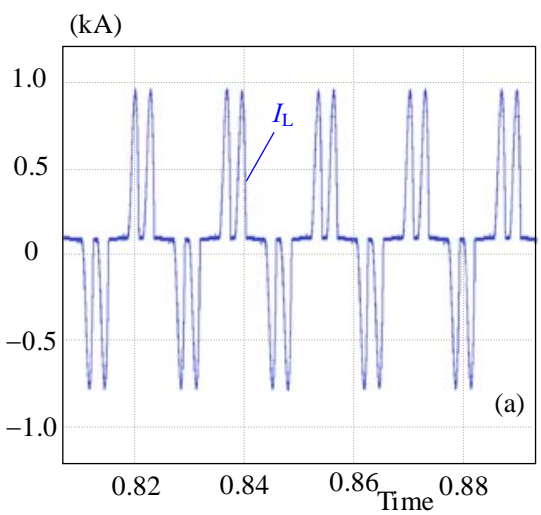

(s)

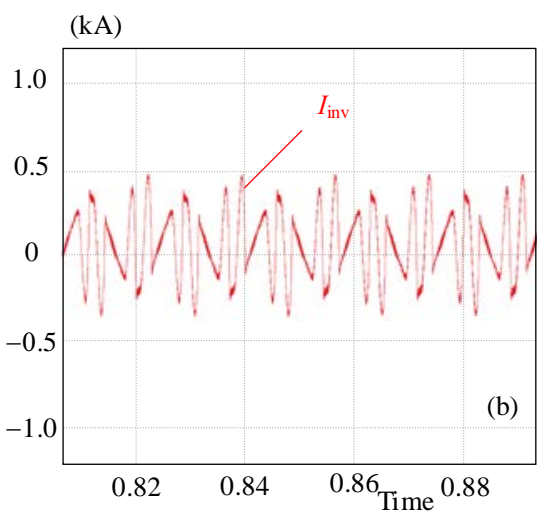

(s)

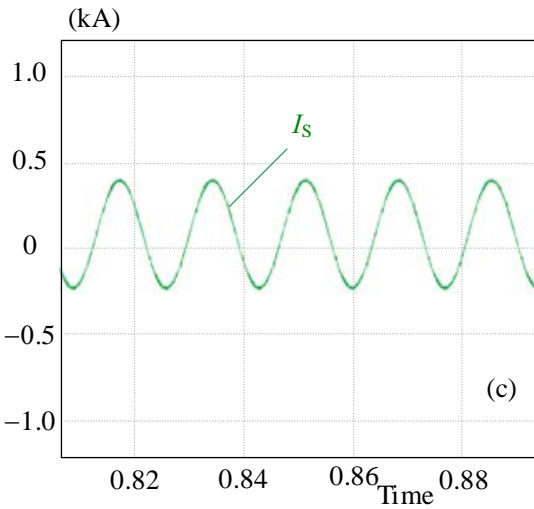

(s)

Fig. 4. (a) - Harmonic load current, (b) - inverter current, (c) - compensated source current
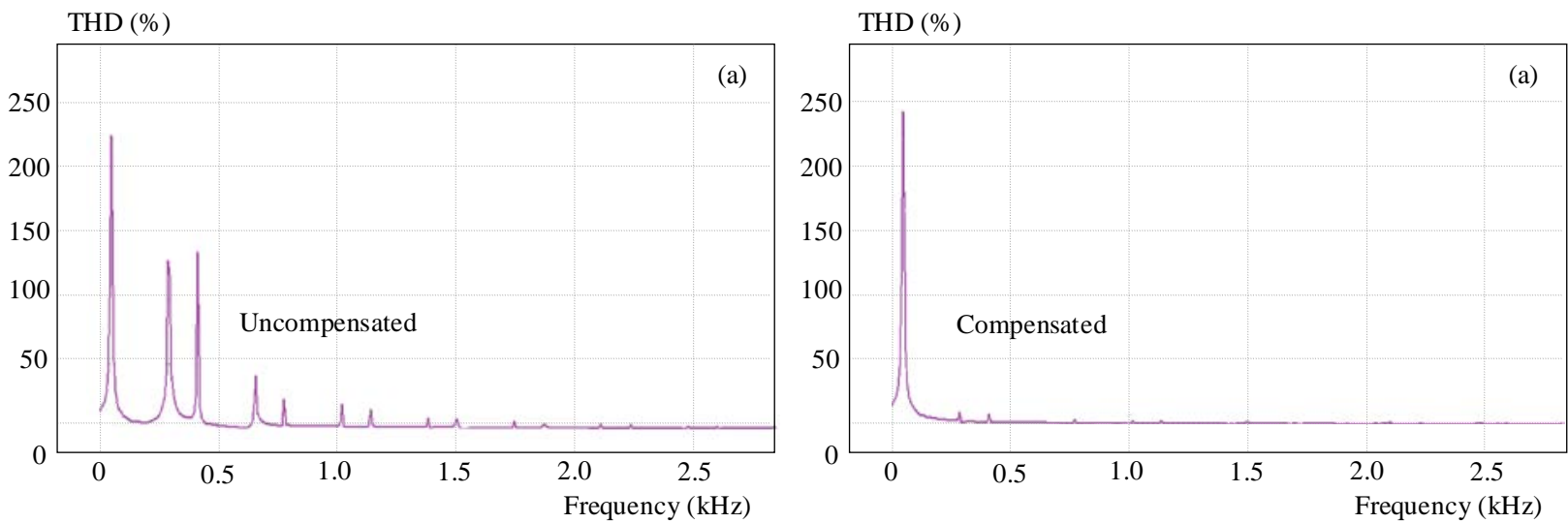

Fig. 5. Frequency spectrum of line current: (a) - load side, (b) - compensated source side

For the weights of functions

$$
\sum_{i=1}^{n} w_{i}=1
$$

should be fulfilled. Thus, the objective functions of this problem can be rewritten as an overall function according to

$$
\begin{aligned}
F_{T}^{\prime}\left(T_{0}, L, C\right)=W_{1} F_{1}^{\prime}+ & W_{2} F_{2}^{\prime}+ \\
& W_{3} F_{3, \text { modified }}^{\prime}+W_{4} F_{4}^{\prime}
\end{aligned}
$$

where $W_{1}, W_{2}, W_{3}$ and $W_{4}$ are weights of each of functions, respectively. $F_{1}^{\prime}, F_{2}^{\prime}$ and $F_{4}^{\prime}$ are normalized objective functions, and $F_{3 \text {,modified }}^{\prime}$ is inverse normalized boost factor function. In fact, because the purpose is minimizing the overall objective function, the third objective function is corrected in equation

$$
F_{3, \text { modified }}\left(T_{0}\right)=1-2 D_{0}=1-2 \frac{T_{0}}{T} .
$$

Because the objective functions have different scales, these functions need to be normalized. Therefore, each of the objective functions are normalized using Equations (23) and (24), and are varied in the range $[0,1]$.

$$
\begin{aligned}
& F_{i}^{*}=\min \left(F_{i}\right), \quad i \in\{1,2, \ldots, n\}, \\
& F_{i}^{\prime}=\frac{F_{i}-F_{i}^{*}}{F_{i}^{\max }-F_{i}^{*}}, i \in\{1,2, \ldots, n\} .
\end{aligned}
$$

\section{IMPLEMENTATION OF MULTI-OBJECTIVE GENETIC ALGORITHM (MOGA)}

The overall objective function using the sum-weighted method is presented in equation

$$
\begin{gathered}
F_{T}^{\prime}\left(T_{0}, L, C\right)=W_{1}\left\{\left[\sum_{n=1}^{6} P_{\mathrm{C}, \mathrm{ZSI}}^{\mathrm{IGBT}_{n}}\right]+P_{\mathrm{C}, \mathrm{ZSI}}^{\mathrm{D} 1}+P_{\mathrm{S}, \mathrm{ZSI}}^{\mathrm{D} 1}\right\}_{\text {norm }} \\
+W_{2}\left\{\alpha \sum_{n=1,2} L_{n}+\beta \sum_{n=1,2} C_{n}\right\}_{\text {norm }}+W_{3}\left\{1-2 \frac{T_{0}}{T}\right\}_{\text {norm }} \\
+W_{4}\left\{\frac{I_{L} T_{0}}{C}+\frac{T_{0}}{L} \frac{1-\left(T_{0} / T\right)}{1-2\left(T_{0} / T\right)} V_{\mathrm{in}}\right\}_{\text {norm }}
\end{gathered}
$$

To avoid extreme amounts of Z-network gain (boost factor) and voltage instability problem, and to preventing negative gain, the amount $\frac{T_{0}}{T}$ should be less than 5.0,

$$
0<\frac{T_{0}}{T}<0.5
$$




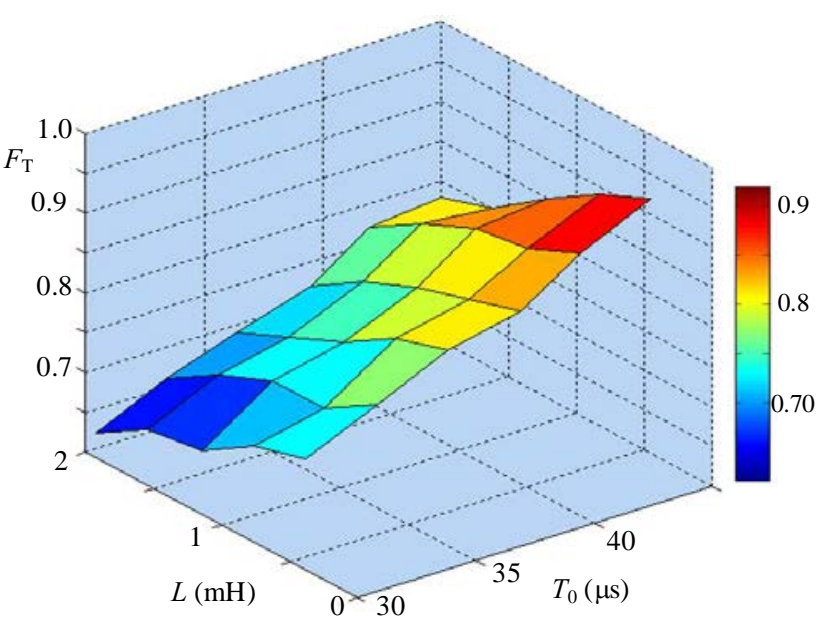

Fig. 6. The variations of overall objective function over Z-source inductance $(\mathrm{L})$ and ST time $\left(T_{0}\right)$

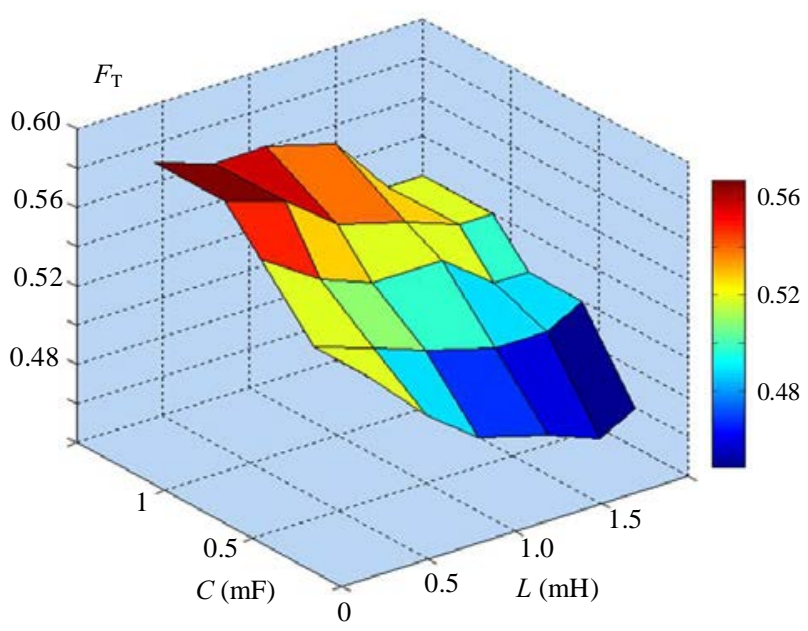

Fig. 7. Frequency spectrum of line current: (a) — load side, (b) compensated source side

To calculate the lower limit of ST time $\left(T_{0}\right)$, the minimum value of DC-link voltage should be calculated. This value is achieved with respect to the maximum output phase voltage.

$$
\begin{aligned}
\hat{v}_{\mathrm{ac}} & =M \frac{\hat{v}_{\mathrm{dc}}}{2} \\
\Longrightarrow \hat{v}_{\mathrm{dc}} & =\frac{2 \hat{v}_{\mathrm{ac}}}{M}
\end{aligned}
$$

where $\hat{v}_{\mathrm{ac}}$ and $\hat{v}_{\mathrm{dc}}$ are the values of maximum output phase voltage and minimum DC-link voltage, respectively. The minimum limit of $\frac{T_{0}}{T}$ can be derived as

$$
\begin{aligned}
\left.\frac{T_{0}}{T}\right|_{\min } & =\frac{1-\left(\hat{v}_{\mathrm{dc}} / v_{\mathrm{in}}\right.}{2}=\frac{1-\left(2 \hat{v}_{\mathrm{dc}} / M v_{\mathrm{in}}\right)}{2} \\
& \Longrightarrow 0.5-\frac{\hat{v}_{\mathrm{dc}}}{M v_{\mathrm{in}}}<\frac{T_{0}}{T}<0.5 .
\end{aligned}
$$

Other constraints and parameters used for optimization the ZSI active filter have been provided in Tabs. 1 and 2 .

The tuned parameters for the genetic algorithm search process in the problem space are presented in Tab. 3.

\section{OPTIMIZATION AND SIMULATION RESULTS}

The genetic algorithm search process is implemented on the overall objective function using MATLAB software. Figure 2 shows the algorithm search for finding the optimal value of the fitness function.

The calculated parameters using genetic algorithm for minimizing the objective function of ZSI active filter, and the amount of switching losses, the cost function, the boost factor and the voltage and current ripples in both genetic algorithm method and non-optimal conditions (typical values that meet their constraints) are presented in Tab. 4.

Figure 3 shows the waveforms of the capacitor voltage $\left(V_{\mathrm{c}}\right)$, the inductor current $\left.\left(\mathrm{I}_{\mathrm{L}}\right)\right)$, and the inverter output voltage before and after using low pass filter $\left(V_{\text {inv1 }}, V_{\text {inv2 }}\right)$.

As can be seen from the results, after optimization with the MOGA, the value of losses function $P_{\mathrm{ZSI}}^{\text {Tot }}$ compared to non-optimal condition is reduced by $39.5 \%$. Also, the inductor current ripple is decreased by $57.03 \%$. However, a slight increase is observed in the voltage ripple equal to $10.81 \%$, which is negligible considering the other benefits. The BF in the optimum condition is equal to 3.125 that is appropriate level. In addition, the value of cost function is reduced using by optimum parameters, which means a reduction in the initial cost of the active filter. Figure 4 shows the current waveforms of the ZSI active power filter.

By using the optimized ZSI active power filter, the level of (THD) in the load current is reduced from $78.39 \%$ to $5.44 \%$, and the power factor is improved from $63.65 \%$ to $97.04 \%$. A comparison between the frequency spectrums before and after compensation is presented in Fig. 5.

By implementing the multi-objective genetic algorithm optimization, the initial cost of ZSI active power filter is reduced by $8.43 \%$. The variations of the overall objective function $\left(F_{T}^{\prime}\right)$ in terms of parameters changes are shown in Figs. 6 to 8.

\section{CONCLUSIONS}

This paper presented a multi-objective optimization on the Z-source active power filter to overcome the ZSI power loss problems and improvement of the active filter performance. The four important objective function including the power losses of the ZSI, The initial cost of the filter elements, the boost factor of the Z-network, the capacitor voltage and inductor current ripples was formed. The multi-objective genetic algorithm (MOGA) 


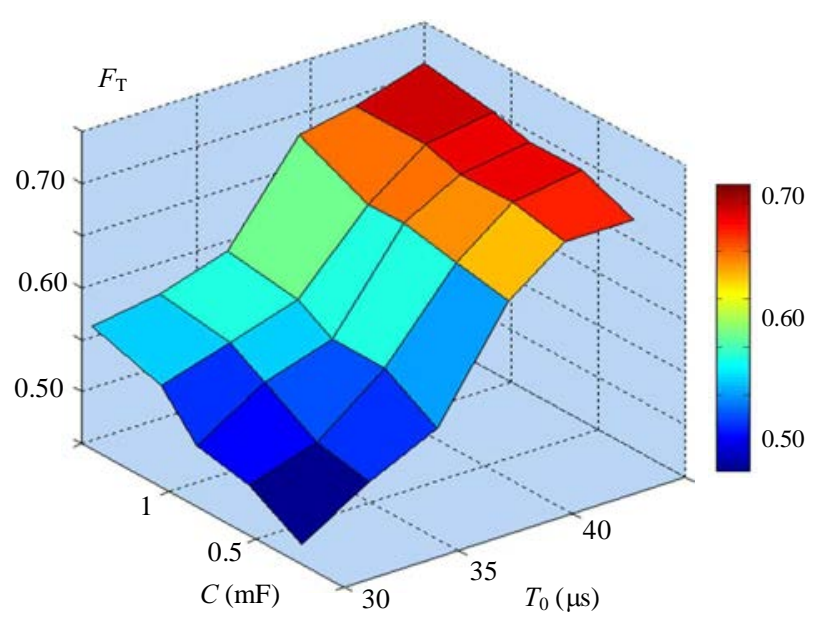

Fig. 8. The variations of overall objective function over Z-source capacitance $(\mathrm{C})$ and $\mathrm{ST}$ time $\left(T_{0}\right)$

was applied to the overall objective function. The analysis of numerical and simulation results indicate a $39.5 \%$ reduction in the losses function, $57.03 \%$ improvement in the inductor current ripple, $8.43 \%$ reduction in the initial cost of impedance network as well as a good level of the boost factor by 3.125 . Also, the operation of Z-source active filter is appropriate in the harmonic compensation of the non-linear load current.

\section{REFERENCES}

[1] KIM, N. H.: Current Controlled PWM for Multilevel Voltage-Source Inverters with Variable and Constant Switching Frequency Regulation Techniques: a Review, Journal of Power Electronics 14 No. 2 (Mar 2014), 302-314.

[2] ROMAN, I. T.-SILVA, L. S. : A Single-Phase Current-Source Inverter with Active Power Filter for Grid-Tied PV Systems, in Proc. IEEE Symp. Power Electronics for Distributed Generation Systems, Aalborg, 2012, pp. 349-356.

[3] TERCIYANLI, A.-AVCI, T.-YILMAZ, I.-ERMIS, C.KOSE, K. N. ACIK, A.et al: A Current Source ConverterBased Active Power Filter for Mitigation of Harmonics at the Interface of Distribution and Transmission Systems, IEEE Tran. Industry Applications 48 No. 4 (May 2012), 1374-1386.

[4] LIU, F.-SAHA, T. K.-KRAUSE, O.-CAO, Y.: Hybrid Inductive and Active Filtering Method for Damping Harmonic Resonance in Distribution Network with Non-Linear Loads, IET Power Electronics 8 No. 9 (Aug 2015), 1616-1624.

[5] LAK, A.-NAZARPOUR, D.-HOSSEINI, S. H.: Z-Source Inverter Based on Constant Maximum Boost Optimized with Particle Swarm Optimization (PSO) Algorithm, Int. Journal on Technical and Physical Problems of Engineering 4 No. 3 (Sep 2012), 100-104.

[6] OH, S. Y.-JUNG, Y.-LIM, Y.: Three-Phase Z-Source Hybrid Active Power Filter System, in Proc. ICEMS, Incheon, 2010, pp. 391-396.

[7] SOON, J. J.-LOW, K. S.: Sigma-Z-Source Inverters, IET Power Electronics 8 No. 5 (Apr 2015), 715-723.
[8] NAG, S. S.-MISHRA, S.: Current-Fed Switched Inverter, IEEE Tran. Industrial Electronics 61 No. 9 (Nov 2013), 4680-4690.

[9] YANG, L.-QIU, D.-ZHANG, B.: High-Performance QuasiZ-Source Inverter with Low Capacitor Voltage Stress and small inductance, IET Power Electronics 8 No. 6 (June 2015), 1061-1067.

[10] PENG, F. Z.: Z-Source Inverter, IEEE Trans. Industry Applications 39 No. 2 (Mar 2003), 504-510.

[11] ZHOU, Y.-LI, H. : A Single-Phase PV Quasi-Z-Source Inverter with Reduced Capacitance using Modified Modulation and Double-Frequency Ripple Suppression Control, IEEE Trans. Power Electronics, to be published.

[12] FRANKE, W. T.-MOHR, M.-FUCHS, F. W. : Comparison of a Z-Source Inverter and a Voltage-Source Inverter Linked with a DC/DC-Boost-Converter for Wind Turbines Concerning their Efficiency and Installed Semiconductor Power, in Proc. IEEE PESC, 2008, pp. 1814-1820.

[13] WEI, W.-HONGPENG, L.-JIAWAN, Z.-DIANGUO, X. : Analysis of Power Losses in Z-Source PV Grid-Connected Inverter, in Proc. IEEE ICPE \& ECCE, Jeju, 2011, pp. 2588-2592.

[14] STEINBRING, M.-PACAS, M.: Increasing the Efficiency of a Single Phase Z-Source Inverter by Utilizing SiC-MOSFETs, in Proc. PCIM Europe, Nuremberg, 2014, pp. 706-712.

[15] OZPINECI, B.-TOLBERT, L. M.-ISLAM, S. K.: Silicon Carbide Power Device Characterization for HEVs, in Proc. Power Electronics in Transportation, Michigan, 2002, pp. 93-97.

16] RABKOWSKI, J.: Improvement of Z-Source Inverter Properties using Advanced PWM Methods, in Proc. conf. Power Electronics and Applications, Barcelona, 2009, pp. 1-9.

[17] LI, J.-LIU, J.-LIU, Z. : Loss Oriented Evaluation and Comparison of Z-Source Inverters using Different Pulse Width Modulation Strategies, in Proc. APCE, Washington, 2009, pp. 851-856.

[18] SHEN, M.-JOSEPH, A.-WANG, J.-PENG, F. Z. : Comparison of Traditional Inverters and Z-Source Inverter for Fuel Cell Vehicles, IEEE Trans. Power Electronics 22 No. 4 (July 2007), 1453-1463.

[19] ZIOLKOWSKI, M.-GRATKOWSKI, S.: Weighted Sum Method and Genetic Algorithm Based Multiobjective Optimization of an Exciter for Magnetic Induction Tomography, in Proc. ISTET, 2009, pp. 1-5.

[20] KONAK, A.-COITB, D. W.-SMITHC, A. E.: Multi-Objective Optimization using Genetic Algorithms: a Tutorial, Elsevier Reliability Engineering and System Safety 91 No. 9 (Jan 2006), 992-1007.

Received 23 December 2015

Seyed Mohsen Hosseini received his BS degree in Electrical Engineering from the Shahed University, Tehran, Iran in 2010 and his MS degree in Electrical Engineering from Semnan University, Semnan, Iran in 2013. His main research interests are power electronic, power converter circuits and power quality.

Yousef Alinejad Beromi received his BS in Electrical Engineering from the KNT University of Tehran, Tehran, Iran and his MS and PhD in Electrical Engineering from the University of Wales College of Cardiff (UWCC), Cardiff, UK, in 1992. He is an associate professor at the Faculty of Electrical and Computer Engineering, Semnan University, Semnan, Iran. 